\title{
Marjolin's Ulcer: Exceptional and Dreadful Complication of Surgical Wounds (About 2 Cases)
}

\author{
Z. Rkiba ${ }^{1},{ }^{2 *}$, A. Messoudi ${ }^{1},{ }^{2}$, A. Abdullah ${ }^{1},{ }^{2}$, M. Rafai ${ }^{1},{ }^{2}$, A. Garch $^{1},{ }^{2}$
}

${ }^{1}$ Orthopedic Department P32, University Hospital Ibn Rochd

${ }^{2}$ University Hassan II, Faculty of Medicine \& Pharmacy of Casablanca, Morocco

DOI: $10.36347 /$ simcr.2021.v09i02.009

| Received: 22.01.2021 | Accepted: 06.02.2021 | Published: 16.02.2021

*Corresponding author: Z. Rkiba

\section{Abstract}

Marjolin's ulcer is a rare and aggressive pathological entity of skin cancers. It is often neglected and therefore poorly managed. It results from a malignant transformation of chronic wounds of a heterogeneous nature. We report two observations of rare forms of squamous cell carcinoma occurring in superinfected and chronic surgical wounds. The mechanism of degeneration is still unknown, various etiological factors are incriminated; all chronic wounds have a potential risk of degeneration. Thus, any scar that does not respond to local treatment for 3 to 6 months is at risk of malignant transformation and requires verification by biopsies performed adequately and repeatedly in order to have an early diagnosis of Marjolin's ulcer. The occurrence of metastases is the main prognostic factor.

Keywords: Marjolin's ulcer - squamous cell carcinoma - surgical wounds.

Copyright $\odot 2021$ The Author(s): This is an open-access article distributed under the terms of the Creative Commons Attribution 4.0 International License (CC BY-NC 4.0) which permits unrestricted use, distribution, and reproduction in any medium for non-commercial use provided the original author and source are credited.

\section{INTRODUCTION}

Marjolin's ulcer is a rare and aggressive pathological entity of skin cancers. It is often neglected and therefore poorly managed. It results from a malignant transformation of chronic wounds of a heterogeneous nature [1]. This transformation may concern burn scars in the majority of cases $(76.5 \%)$ but also, more rarely, chronic traumatic wounds $(8.1 \%)$, venous ulcers $(6.8 \%)$ and other types of chronic inflammatory lesions $[2,3]$. The predominant histological type remains squamous cell carcinoma (SCC). We report two observations of rare forms of squamous cell carcinoma occurring in superinfected and chronic surgical wounds.

\section{Case Report}

\section{Case 1}

We report the case of a 64-year-old diabetic patient under treatment. This patient suffered a serious trauma to her right leg following a road accident in June 2016. Initially the patient was operated for a complex fracture of the leg by internal osteosynthesis. A sepsis around the fourth month complicated the evolution and required the removal of the material and the placement of an external fixator (Figure-1). Healing was obtained after a long period of local care. After one year, the external fixator was removed. However, the evolution was again marked by the appearance of septic pseudarthrosis for which the patient benefited from osteosynthesis with a new external fixator. On another occasion, wound healing was difficult under daily local care for six months. Removal of the new external fixator was done after nine months. The patient developed chronic osteitis with an active fistula facing the inner side of the proximal third of the leg. For the active evolution of the osteitis despite local care and antibiotic therapy on demand chronic osteitis, in January 2020, the patient was operated on using the Masquelet technique (resection of the osteitis and filling with an antibiotic cement spacer). Once again, and after three months of local care, we noted an absence of healing with evolution of the edges towards ulcerations (Figure-2). Faced with this aspect of scarring, we performed a surgical biopsy where the diagnosis of squamous cell carcinoma was suggested. The patient and her family completely refused this diagnosis, where a new biopsy was performed and the diagnosis was confirmed. The case was discussed in the multidisciplinary consultation meeting (RCP). An extension assessment (clinical, paraclinical) did not discover any secondary localizations. In view of the local condition, the notion of multiple surgical interventions with potential risk of local dissemination and after consent; the patient underwent an amputation in the lower third of the right thigh. The postoperative sequelae were simple. After eight months, the patient is 
doing well with a normal first follow-up assessment. An orthopedic gait prosthesis is being made.

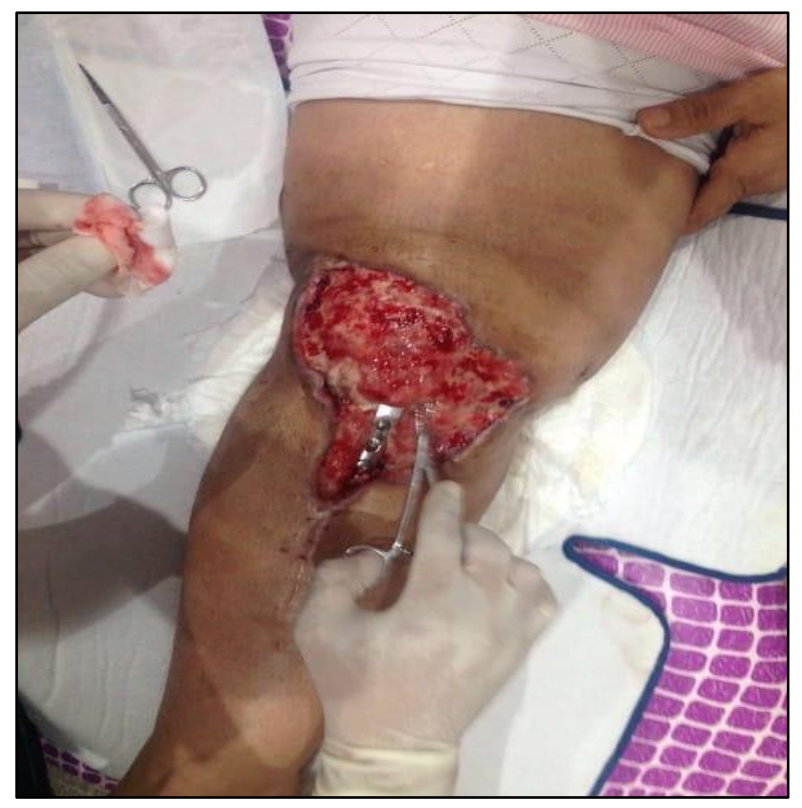

Fig-1: Sepsis on osteosynthesis materials

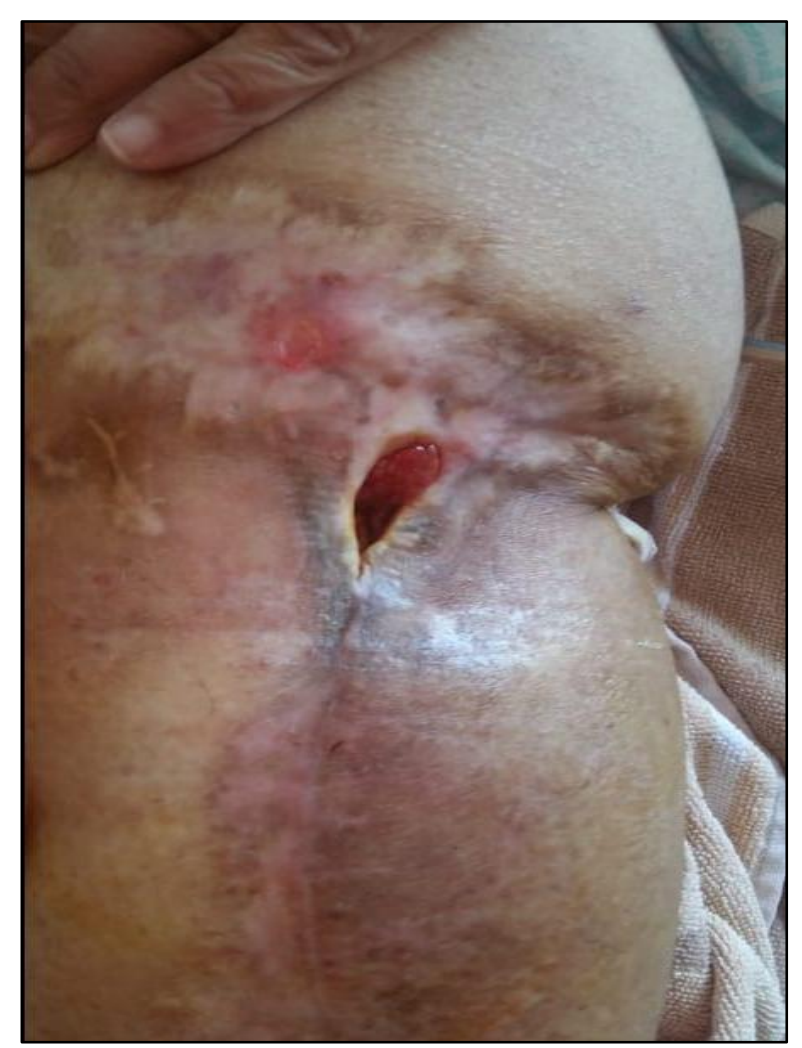

Fig-2: Absence of healing with evolution of the edges towards ulcerations

Case 2

Male patient aged 58 years old, walking with a right equine varus clubfoot from a young age. Operated for a right forefoot trauma form 14 years. The surgical wound never healed and was poorly managed and neglected by the patient, with aggressive footwear and repetitive pressure on the scar. The examination noted an equinus deformity of the forefoot with the presence of an ulcerous blistering lesion extending over the entire dorsal surface of the forefoot, which was part of an operative scar (Figure-3). The general clinical examination did not find any regional adenopathies or associated local or locoregional lesions. A surgical skin biopsy confirmed the clinically suspected diagnosis by objectivizing a well-differentiated infiltrating squamous cell carcinoma. Magnetic resonance imaging (MRI) of the limb showed osteoarticular invasion of the entire forefoot. The extension test did not show any metastases. The patient underwent a mid-leg amputation with simple post-operative sequelae. After eight months, the patient is autonomous with the help of an orthopedic walking prosthesis, and his follow-up assessment did not reveal any metastases.

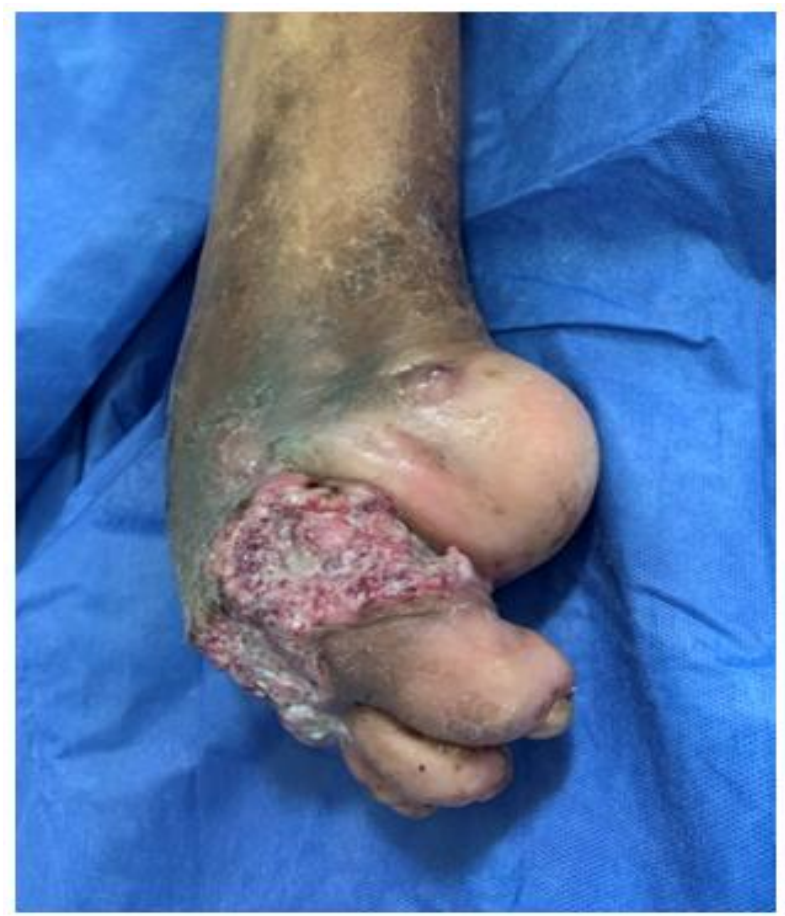

Fig-3: Equinus deformity of the forefoot with the presence of an ulcerous blistering lesion extending over the entire dorsal surface of the forefoot

\section{DisCUSSION}

Aulus Cornelius Celsus [4] is the author of the first treatise on medicine in antiquity, in which he describes malignant lesions in the epithelium on burn scars. The term Marjolin's ulcer was attributed to Jean Nicolas Marjolin (1780-1850), a French physician, coauthor of the "Dictionary of Medicine" in 1828, who described in the section on ulceration; chronic ulcers occurring on scar tissue without prejudging their malignancy or their relation to burn scars $[5,6]$. In 1833, the recognition of the specific association between malignant ulcers and burn scars was attributed to Caesar Hawkins [7], an English surgeon, who described in his article this entity called "warty ulcer occurring on scars". In 1850, the year of Marjolin's death, Robert WS [8], Professor of Surgery at Trinity 
University in Dublin, used the term "Marjolin's warty ulcer" to describe an ulcerated lesion developing on burn scars. In 1903, Chalmers Da Costa J [9], professor at Jefferson University in Philadelphia, also defined Marjolin ulcer as a carcinoma occurring in areas of chronic inflammation. As a result of these two publications, the term Marjolin ulcer has become generally accepted and used in the literature until today. Currently it describes all carcinomas that develop in scar tissue, ulcers and chronic inflammatory lesions such as orifices of chronic osteomyelitis and bedsores [10].

The incidence of Marjolin's ulcer is between 1 and $2 \%$. The malignant transformation of chronic traumatic wounds remains exceptional, very few cases have been published in the literature, the majority of cases occur in the aftermath of burns. Allepot K et al., [3] published a case of marjolin ulcer following a traffic accident with a latency period of 15 years. All chronic wounds have a potential risk of degeneration. Thus, any scar that does not respond to local treatment for 3 to 6 months is at risk of malignant transformation and requires verification by biopsies performed adequately and repeatedly in order to have an early diagnosis of Marjolin ulcer. Malignant degeneration generally occurs over a period of more than 10 years with an average of 30 years, however Marjolin ulcer is a fifthand sixth-decade tumor $[12,13]$. But exceptions are not uncommon, it can develop rapidly, be multiple, recur at a distance or be rapidly fatal [3]. Marjolin ulcer can be subacute (malignant transformation within 12 months of the initial lesion) or chronic [1]. The shortest latency period described in the literature was three weeks [14]. It seems that the latency period is shorter in elderly subjects, and the extremities are most frequently affected $[15,16]$. Marjolin ulcer is reported to be more aggressive than primary skin tumors, with up to $30 \%$ having locoregional adenopathy and distant metastases at diagnosis [17]. The mechanism of degeneration is still unknown, various etiological factors are incriminated such as the local release of mutagenic toxins from necrotic tissue, a decrease in the number of immune system cells (T-lymphocytes), a decrease in vascularization, all these factors allow tumor cells to escape immune detection and become aggressive and prone to metastasis [1]. It is highly likely that pathogenesis is related to multiple environmental, immunological and genetic factors. The lesion in our first case would probably be secondary to chronic irritation (multiple surgeries and repeated local care over a four-year period. Our second case had a mechanical notion of direct repetitive pressure on the scar over a long period of time leading to chronic irritation and probably malignant degeneration. Due to their greater aggressiveness, these tumors require early diagnosis and adequate management in order to increase the survival rate. The occurrence of metastases is the main prognostic factor. Surgical treatment can range from wide excision to amputation. In the case of metastases, adjuvant or neoadjuvant treatment (radiotherapy and chemotherapy) may be recommended. The recurrence rate is not as rare, according to the literature this rate is higher in Marjolin ulcer than in primary skin cancers [18]. Kowel et al., [19] reported a rate of $16 \%$ in their meta-analysis, and this rate is as high as $50 \%$ in some studies.

\section{CONCLUSION}

Malignant degeneration of traumatic or surgical wounds is very rare, it is an aggressive form of Marjolin ulcer. Any chronic wound can be the site of a malignant transformation and requires rapid diagnosis through multiple biopsies and optimal treatment to avoid prognostic metastases.

Declaration of Competing Interest: The authors report no declarations of interest.

\section{REFERENCES}

1. Bazaliński D, Przybek-Mita J, Barańska B, Więch P. Marjolin's ulcer in chronic wounds-review of available literature. Contemporary Oncology. 2017;21(3):197.

2. Kerr-Valentic MA, Samimi K, Rohlen BH, Agarwal JP, Rockwell WB. Marjolin's ulcer: modern analysis of an ancient problem. Plastic and reconstructive surgery. 2009 Jan 1;123(1):184-91.

3. Allepot K, Curings P, Viard R, Vincent PL, Voulliaume D. Piège diagnostique: l'ulcère de Marjolin d'apparition précoce, multiple ou récidivant. À propos d'une série de 8 patients (16 tumeurs) et revue de la littérature. InAnnales de Chirurgie Plastique Esthétique 2020 Jul 11. Elsevier Masson.

4. Novick M, Gard DA, Hardy SB, Spira M. Burn scar carcinoma: a review and analysis of 46 cases. Journal of Trauma and Acute Care Surgery. 1977 Oct 1;17(10):809-17.

5. Sharma A, Schwartz RA, Swan KG. Marjolin's warty ulcer. Journal of surgical oncology. 2011 Feb 1;103(2):193-5.

6. Marjolin, J. (1828). Dictionnaire de Medicine. Adelon N (ed.). Bechet, Paris, 31-50.

7. Hawkins, C. (1833). On warty tumors in cicatrices. Lond Med Gaz, 13:481-2

8. Smith, R. W. (1850). Observations upon the warty ulcer of Marjolin. Dublin Quart J Med Sci. 9: 257 75.

9. Da Costa, J. C. (1903). Carcinomatous changes in an area of chronic ulceration, or Marjolin's ulcer. Ann Surg. 37: 496.

10. Kózka M, Spałkowska M, Balawender R, Sroga J, Dobosz J. Rak kolczystokomórkowy w bliźnie pooparzeniowej--opis przypadku owrzodzenia Marjolina. Leczenie Ran. 2013 Jul 1;10(3).

11. Treves N. The development of cancer in burn scars: an analysis and report of thirty-four cases. Surg Gynecol Obstet. 1930;51:749-82. 
12. Meaume S, Fromantin I, Teot L. Neoplastic wounds and degenerescence. Journal of tissue viability. 2013 Nov 1;22(4):122-30.

13. Fleming MD, Hunt JL, Purdue GF, Sandstad J. Marjolin's ulcer: a review and reevaluation of a difficult problem. The Journal of burn care \& rehabilitation. 1990 Sep 1;11(5):460-9.

14. Mohammadi AA, Foroutan A, Mohammadi S, Anbardar MH. An odd very early Marjolin's ulcer after minimal hand burn. Annals of burns and fire disasters. 2017 Sep 30;30(3):218.

15. Chalya PL, Mabula JB, Gilyoma JM, Rambau P, Masalu N, Simbila S. Early Marjolin's ulcer developing in a penile human bite scar of an adult patient presenting at Bugando Medical Centre, Tanzania: A case report. Tanzania journal of health research. 2012 Dec 24;14(4).
16. Mohammadi, A. A., \& Johari, H. G. (2009). Letters to the Editor. J Trauma Acute Care Surg, 66(6):1746-7.

17. Shen R, Zhang J, Zhang F, Du Y, Liang W, Xu L, Du X, Chen P, Chen X. Clinical characteristics and therapeutic analysis of 51 patients with Marjolin's ulcers. Experimental and therapeutic medicine. 2015 Oct 1;10(4):1364-74.

18. Ogawa B, Chen M, Margolis J, Schiller FJ, Schnall SB. Marjolin's ulcer arising at the elbow: a case report and literature review. Hand. 2006 Dec;1(2):89-93.

19. Kowal-Vern A, Criswell BK. Burn scar neoplasms: a literature review and statistical analysis. Burns. 2005 Jun 1;31(4):403-13. 